\title{
Role of Women Led Sanitation in Community Development
}

\author{
Madhusudan N. Pandya ${ }^{1}$ and Parag Sunil Shukla ${ }^{2}$
}

\begin{abstract}
Mahatma Gandhiji's visualisation of Clean India is taking a shape gradually and especially since the launch of the Swachh Bharat Mission on 2nd October 2014, the overwhelming participation from citizens across India in various aspects of 'Swachhata' has been observed. So the journey of Swachh Bharat has emerged as a critical means to engage citizens more intensely in improvement of health and hygiene conditions. Gender is an important notion in sanitation and hygiene because women often have the primary responsibility for facilities and practices in the household. As a result, they often experience a significant extra burden.

Disproportionate burden is faced by women especially shortage of or the non-availability of sanitation facilities that can be also called as "Gender-based sanitation insecurity." Women face threat to their life and feel unsafe while seeking toilet facility or while going out for open defecation. This leads to consumption of less food and water by the women to minimise the need to exit the home to use toilets. As per census 2011, more than fifty percent of the India's population defecated in the open and recent data showed that about 60 percent of rural households and 89 per cent of urban households have access to toilets (Economic Survey 2016-2017).

In this research paper an attempt has been made by the researcher to review the Sanitation Status in Selected Cities, Sanitation and the Gender Challenge and the status of swachhataabhiyan and the relationship between women contribution in sustainable community development through economic and social development as well as environment protection.
\end{abstract}

Keywords:Swachh Bharat, SwachhataAbhiyan

\section{Introduction:}

Water Supply and Sanitation Collaborative Council (WSSCC) launched the Global Sanitation Fund (GSF) in the year 2008 which aimed at the basic principle to serve the most vulnerable, ensure Gender equality, and addressing the needs of women and girls in the sanitation and hygiene behaviour change programmes (Isobel Davis, 2016).

According to IyerParameswaran (2017) the November 19, was World Toilet Day and a good time to take stock of how the Swachh Bharat Mission (SBM) has learned and adapted over time. The SBM has witnessed much success and is on its way to making the "impossible" achievable. The number of open Defecation Free (ODF) villages has increased by 10 times to more than 2.75 lakh in the last three years. Nearly 250 districts are ODF, up from four at the start of the mission. Sanitation coverage has increased from 39 percent to more than 71 percent. These successes have been on the back of a continuous feedback that the Ministry of Drinking Water and Sanitation (MDWS), together with states and civil

1,2 Assistant Professors of Commerce \& Business Management, Department of Commerce \& Business Management, Faculty of Commerce, The Maharaja Sayajirao University of Baroda, Baroda, The M.S. University of Baroda, Baroda society organizations, has managed to establish. The districts, being the primary unit of convergence of different programmes, especially education and health, have been at the centre of the learning and sharing process. Several workshops have been organized by MDWS where collectors and other district officials share innovative ideas for better implementation and sustainability of ODF villages and districts. ZilaSwachh Bharat Preraks, young professionals working with district administrations in all districts of the country aid in the district-to-district connect. Regular interaction with civil society organizations, development partners and locally elected representatives also takes place. The MDWS has also developed a knowledge management portal called the SwachhSangraha, a repository of all information from the field on Swachh Bharat, aimed at being the Google for SBM.

Get everyone involved, so it becomes everyone's business Learning from the success of field motivators in mobilizing the community, the MDWS has empaneled 36 Knowledge Re source Centers to be hired by states to train field motivators called Swachhagrahis, with a goal of having at least one such motivator in each village of the country. There are 300,000 of them, and the number is rising. The SBM is becoming a people's movement. Probably the biggest embodiment of 
this is the Mubarakpur village in Bijnor, UP, where villagers cumulatively turned down the Rs 17.5 lakh incentive from the government for their toilets and chose to pool in their own funds. On World Toilet Day, there is a need to rededication of people to the biggest learning of usage is paramount and self-reminder about that adapting swachhata is very important for health. This is what makes Swachh Bharat Mission the most unique sanitation programme in the world (IyerParameswaran, 2017- Times of India dated 21/11/2017).

Though the Swachh Bharat Mission (SBM) is people's movement for improving health and hygiene, still there are instances that girls and women face situation where access to sanitation facilities is not easy and even it is unsafe. The desire for privacy during bathing and defecation is different in case of girls and women than men and thus, non-availability of proper sanitation facilities create helpless situation for females and led to the risk of faucal-orally transmitted diseases, uro-genital tract infections, urinary incontinence and chronic constipation (Mudey $\mathrm{AB}$ et., al. 2010).In practice the promoters of swachhtararely encourage the women to participate in water and sanitation committees, does not guarantee their participation and even women who participate in the community meetings for creating awareness and promotion of improved sanitation facilities not resulted in their participation in community level decision making. So, the age, position in the family and societal and cultural barriers for femalesare some of the factors that determine participation of women in the sanitation decision making (Acharya, DR., 2010).

In this study researcher has reviewed the status of swachhataabhiyan and the relationship between women led sanitation and sustainable development.

\section{Review of Literature:}

Woman's inclusion in community decisionmaking for considering women's needs when determining the sanitation solution may not be adequately taken into consideration and it could be an important factor, as this has an impact on developing the most appropriatelong-term sustainable solutions (Isobel Davis, 2016). Considering the Gender Equality Index the African decision-makers need to concentrateand address some important obstacles that prevent African women from engaging on alevel playing field with men, and better focus its genderrelatedpolicy dialogue and interventions (African Development Bank Group, 2015).Routray, Parimita. (2017) examined the association between women's decision-making autonomy and latrine adoption in rural areas of Odisha and found that women's enjoy less freedom of making choice and decision with respect to installation of sanitation facility due to prevailing socio-cultural and economic constraints, and power hierarchies among household members (Routray, Parimita, 2017).Goel, Palaket., al conducted research study and concluded that there is need to educate women about how to livehealthy reproductive life using satisfactory absorbent material and its consequences during menstruation period as well as how to manage Menstrual Hygiene situation (Goel, Palak, et., al. 2017). Dr. Pandit, Dipanwitaet., al. (2014) identified that good hygienic practices such as the use of sanitary pads and adequate washing of the genital area are essential during menstruation. Menstrual hygiene and management will directly contribute to the Millennium Development Goal (Dr. Pandit, Dipanwitaet., al., (2014).Seenivasan, P. et., al (2016) assessed the knowledge, practices and attitude related to menstruation and highlighted the fact that the adolescents need to have accurate and adequate information about menstruation and its appropriate management (Seenivasan, $\mathrm{P}$. et., al, 2016).

Review of Sanitation Status in Selected Cities:

Quality Council of India (QCI) was commissioned by The Ministry of Urban Development (MoUD) to conduct the 'SwachhSurvekshan 2017' survey of 500 cities to keep an eye on the progress and impact of Swachh Bharat Mission.The hidden objective is to cultivate spirit of competition among the cities and offers a comprehensive assessment of their sanitation statusbased on cleanliness and sanitation. The ranking of the cities was based on data-collection from 3 sources,i.e. First,Municipal documentation carried 45percent weightage and can fetch a total of 900 marks. Second, the Direct observation carried 25percent weightage and can fetch a total of 500 marks, and third is Citizen feedback data carried 30percent weightage and can fetch a total of 600 marks.Out of 500 cities, 434 cities participated in SwachhSurvekshan 2017 and based on the scores obtained the ranking of top 25 the cities, in descending order, is shown in the table number 1 (Ministry of Urban Development Government of India Survey 'SwachhSurvekshan 2017'). 
Table No. 1:Ranking of top 25 the cities participated in Swachh Survekshan 2017

\begin{tabular}{|c|c|c|c|c|c|}
\hline Ranking & City (ULB) & $\begin{array}{c}\text { Municipal } \\
\text { Documentation } \\
\text { (900 Marks) }\end{array}$ & $\begin{array}{l}\text { Independent } \\
\text { Observation } \\
\text { (500 Marks) }\end{array}$ & $\begin{array}{c}\text { Citizen } \\
\text { Feedback \& } \\
\text { Swachhta } \\
\text { App } \\
\text { (600 Marks) }\end{array}$ & $\begin{array}{l}\text { Total Score } \\
\text { (2000 Marks) }\end{array}$ \\
\hline 1 & Indore & 875.00 & 435.78 & 496.94 & 1807.72 \\
\hline 2 & Bhopal & 829.58 & 483.00 & 487.85 & 1800.43 \\
\hline 3 & Visakhapatnam (Vizag) & 869.00 & 458.51 & 469.02 & 1796.53 \\
\hline 4 & Surat & 848.58 & 424.66 & 489.25 & 1762.49 \\
\hline 5 & Mysuru (Mysore) & 833.37 & 460.25 & 449.74 & 1743.36 \\
\hline 6 & Tiruchirappalli (Trichy) & 854.37 & 436.41 & 425.06 & 1715.84 \\
\hline 7 & $\begin{array}{l}\text { New Delhi Municipal Council } \\
\text { (NDMC) }\end{array}$ & 819.95 & 426.88 & 461.13 & 1707.96 \\
\hline 8 & Navi Mumbai & 856.13 & 392.24 & 456.77 & 1705.14 \\
\hline 9 & Tirupati & 809.13 & 465.76 & 428.97 & 1703.86 \\
\hline 10 & Vadodara & 837.25 & 406.24 & 459.58 & 1703.07 \\
\hline 11 & Chandigarh & 883.42 & 438.98 & 379.05 & 1701.45 \\
\hline 12 & Ujjain & 832.32 & 390.78 & 467.41 & 1690.51 \\
\hline 13 & Pune & 870.39 & 409.92 & 379.87 & 1660.19 \\
\hline 14 & Amdavad (Ahmedabad) & 806.48 & 455.60 & 394.94 & 1657.02 \\
\hline 15 & Ambikapur & 778.68 & 373.07 & 501.51 & 1653.26 \\
\hline 16 & Coimbatore & 866.58 & 431.34 & 352.16 & 1650.08 \\
\hline 17 & Khargone & 825.00 & 405.70 & 407.93 & 1638.63 \\
\hline 18 & Rajkot (M. Corp) & 812.58 & 401.77 & 423.88 & 1638.23 \\
\hline 19 & Vijayawada & 799.00 & 406.38 & 418.80 & 1624.18 \\
\hline 20 & Gandhinagar (NA) & 718.04 & 426.16 & 468.52 & 1612.72 \\
\hline 21 & Jabalpur & 847.26 & 356.00 & 406.07 & 1609.33 \\
\hline 22 & $\begin{array}{l}\text { Greater Hyderabad Municipal } \\
\text { Corporation (GHMC) }\end{array}$ & 733.89 & 428.00 & 443.40 & 1605.30 \\
\hline 23 & Sagar & 779.00 & 391.21 & 433.20 & 1603.41 \\
\hline 24 & Murwara (Katni) & 716.95 & 404.14 & 455.45 & 1576.54 \\
\hline 25 & Navsari & 726.16 & 380.68 & 460.69 & 1567.52 \\
\hline
\end{tabular}

Source: Ministry of Urban Development Government of India Survey 'SwachhSurvekshan 2017'.

As given in the table number 1 the assessment of cities was done considering the awareness about sanitation and cleanliness and the appropriate documentation by municipal authorities. The score was assigned based on five parameters includes management of solid waste by municipal authorities through sweeping, collection and its movement through proper transportation arrangements; the processing and disposal of solid waste management; the monitoring of open defection and free toilets in cities; capacity building, and sharing of information, education, communication to bring behavioural change among people. Such stakeholder participatory reform driven process helpful in benchmarking and sharing of information for monitoring and evaluating the progress towards swachhataabhiyan.

The Government can identify areas of improvement and help the cities to learn about the best practices being implemented by other cities and adopt as per their own requirement (Ministry of Urban Development Government of India Survey 'SwachhSurvekshan 2017').

\section{Sanitation and the Gender Challenge:}

Considering the challenges involved in gender and sanitation it is observed that the poor sanitation and hygiene has disproportionate impact on women andgirls. The aspects of impact on women and girls includes physical stress and psycho-social stress due to infrequent visits to the 
toilet; the risk involved with feeling of unsafe while searching a place to go often to toilet after dark or early in the morning; and dropping out of school at the onset of menstruation due to a lack of safe and private disposal facilities. It is again observed that the women's participation and voice are marginalised community decisionmaking, which affects their ability to influence decisions around sanitation and hygiene facilities and services. There is arelatively widespread communication in the society that women's empowerments important for more sustainable sanitation and hygiene solutions for both sexes (Water and Sanitation Program, 2010). The different opportunities and privileges are available to men and women in different conditions which result in to different wage earning opportunities as well as they do not have the same access to education and are not always equal before the law.

\section{Women: Key towards Achievement Sustainable} Development Goals:

The below given Figure number 1 shows the relationship between women and sustainable community development and it became clear that how women are affected by Sustainable Development Goals (SDGs) as well ashow women and girls can and will be key to achieving each of these goals.

Women can contribute to achieve the sustainable development goals through three interrelated pillars of economic development, social development and environmental protection.

\section{Figure No. 1: The Relationship Between Women and Sustainable Community Development}

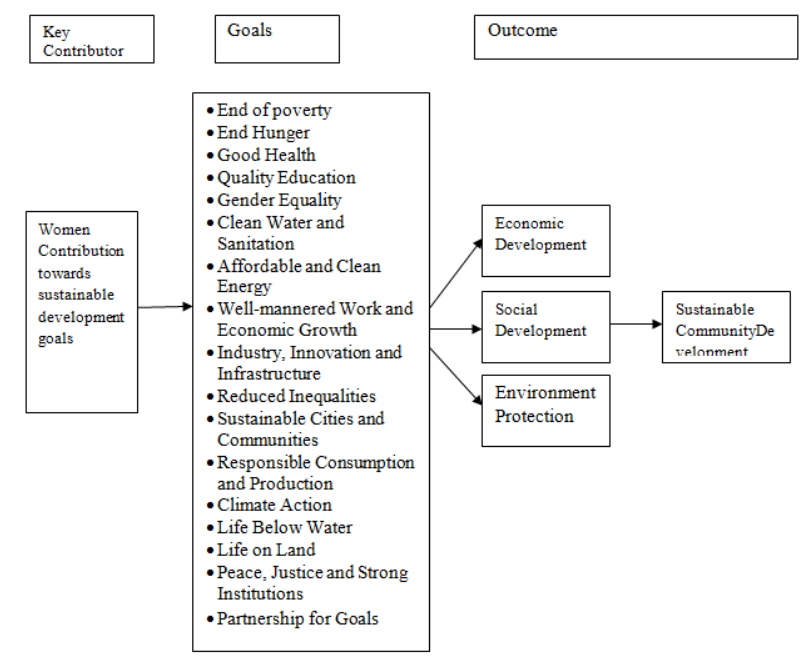

The discrimination based on gender is responsible for poverty all over the world which makes women poor and keeps them deprived of basic rights and keep away from a chance to grab opportunities to live being as well. Women make significant contributions every day from bringing an income to her household as an employed wage earner, to creating jobs as an entrepreneur, to taking care of her family and elders.

Households headed by women may not eat enough simply because women earn at lower levels and are less prepared to cope with sudden crisis. Nourishment is not just about the quantity of food, but its quality. In poor households, women can be less likely to get the nutrients they need, including to manage the physical demands of pregnancy and breastfeeding. Gender inequality intersects with inadequate health care, insufficient education and limited income to drive these deprivations.

The highest attainable standard of health is a fundamental right of every person. Gender-based discrimination, however, undercuts this right. It can render women more susceptible to sickness and less likely to obtain care, for reasons ranging from affordability to social conventions keeping them at home.

Education is a right. It empowers individuals to increase their well-being and contributes to broader social and economic gains. Women entering higher levels of education, and greater equality led to economic cooperation and development. For all girls and boys, men and women, education must be available across their lifetimes.

Deep legal and legislative changes are needed to ensure women's rights around the world. In many nations, gender discrimination is still woven through legal and social norms. Severe gender disparities remain in economic and political realms. Meanwhile, violence against women is a pandemic affecting all countries, even those that have made laudable progress in other areas. Women have a right to equality in all areas. It must be embedded across legal systems, upheld in both laws and legal practices since all areas of life relate to gender equality, efforts must be made to cut the roots of gender discrimination wherever they appear.

A drink of water sustains human life, but only if it is safe and affordable. For women, inadequate water supplies pose additional burdens.

Poor quality sanitation including open defecation can pollute water and spread disease and lack of separate facilities for girls can be a major reason for parents keeping them at home. Ensuring water and sanitation for all is the goal; achieving it must take all dimensions specific to women and 
girls on board and involve them directly in the process.

Sustainable modern energy fuels development, from the light that allows a child to do her homework to streetlamps allowing women to travel safely home at night. Universal access requires energy to be affordable and reliable. Generating it must not irreversibly harm the environment. In households, women are often the primary energy managers. When modern sources are not available, they spend hours each day collecting fuel to cook and heat their homes. Many suffer poor health through indoor air pollution generated through use of stove. As primary energy managers in households, women could play powerful roles in extending sustainable modern energy. All elements of energy planning and policy-making need to factor in gender dimensions and actively advance women's leadership.

An inclusive, sustainable economy fosters growth with benefits for all. It does not harm the environment and uses resources judiciously so they will remain for generations to come. In an inclusive economy, decent work means a living wage, workplace safety and protection against discrimination. Yet, globally, women still work at lower rates than men. Gender stereotypes often define what 'women's work' is and can channel women into some of the worst jobs. Women must have equal access to decent work, productive resources and financial services, as well as an equal voice in economic decisions. This includes advocating for legislation on equal pay for equal work, better access to employment opportunities, safety from sexual harassment in the workplace, and other critical rights.

Economic development builds on infrastructure that needs to be sustainable in its construction and use including through environmentally sound technologies and resilient to future risks.

All elements of planning, building and financing must take gender dimensions into account, so that women have facilities and services essential to their needs and rights. New and existing industries must pursue sustainable paths, including through innovation and upgraded technology. From the factory floor to the hightech lab, women must have equal opportunities in building a shared, sustainable future.

Inequalities have widened across and within many countries, and today, more women are in the workforce, in politics, in leadership roles, breaking stereotypes and societal taboos. Yet, gender discrimination makes women prone to deeper disparities. Further, gender discrimination can intersect with other types, such as regarding age, disability ethnicity, economic status and so on, multiplying the burden of inequalities many times over. Social norms that treat women as second-class citizens in many cases translate into structural obstacles to progress, such as laws that fail to punish perpetrators of gender-based violence.

The world today is urbanizing at rates unprecedented in history. For many men and women, the chance to move to a city is a chance for a better life-a larger income, more interesting employment, a more comfortable residence and ready access to modern amenities. Yet cities are also places of deep inequality and despair. New migrants, many of them women, can end up in overbuilt slums, poorly connected to public transport or essential services such as clean water. Life becomes dangerous and unhealthy, with many obstacles to gaining a secure foothold in the urban economy. Natural disasters kill more women than men and kill women at a younger age than men. If she survives a disaster such as a flood or earthquake, a woman will likely have fewer options to recover.

Unsustainable consumption and production patterns, historically concentrated in countries and groups with the highest standards of living, have pushed the world against its planetary boundaries. Surpassing these limits poses the risk of resources being lost forever. Climate change, impacted by greenhouse gas emissions, poses escalating threats.

Women in consumption and production must have equal access to means such as land and technology that can boost their standard of living. Women at large must assume equal leadership in striking a better balance-in parliaments and boardrooms, in their communities and families.

Climate change poses growing risks. Catastrophic storms destroy lives and homes. Droughts pressure rural livelihoods. Sea level rise threatens low-lying areas. Adequate education and employment, for example, help build safety nets against disaster. The most vulnerable people are most at risk from climate change, including many poor women. For them, the impacts are already a daily reality. Many spend increasingly long hours hunting for food, fuel and water, or struggling to grow crops. When disasters strike, women are far more likely to perish. Through their experiences and traditional knowledge as stewards of many natural resources, women can offer valuable insights into better managing the climate and its risks. 
Over the longer term, oceanic changes can result in globally significant climate shifts. For now, the most immediate impacts are felt in coastal communities and among those who depend on oceans for livelihoods. Women face the risks of ocean degradation with fewer assets and alternatives for livelihoods, and less resilience against the loss of natural resources. All strategies for conservation and sustainable use need to respond to these vulnerabilities. Women's limited representation in marine science must be corrected towards tapping all perspectives for fair and durable solutions.

Globally, forests have been cut at devastatingly fast rates, often for profits that bypass local communities. Land use practices have led to land degradation and desertification, as have droughts, including those linked to climate change. All these patterns undercut resources that sustain environmental health and human wellbeing. Women can be among the first and most affected, often charged with making up shortfalls in food and fuel. Their limited ownership of land reduces their capacity to adapt to losses or make decisions about how land is used-for the benefit of themselves and the environment. Despite these constraints, women play a critical role as stewards of the land, comprising much of the agricultural labour force in developing countries. They may be primary collectors of resources such as wood for fuel, as well as wild foods and herbs for medicines. Their knowledge about traditional practices that are inherently sustainable, however, is often excluded from decisions about sustainable ecosystems. Peaceful and inclusive societies uphold the rule of law and ensure equal access to justice. They protect people from all forms of violence, including gender-based violence, and control corruption and organized crime. During wars or conflict, women often have fewer resources to protect themselves and, with children, frequently make up the majority of displaced and refugee populations. War tactics such as sexual violence specifically target them. Women have made strides in representation in decision-making, in some peace processes as well as governance more broadly.

The SDGs will mean little without the means to implement them. Finance, technology, capacities, partnerships and data are among the primary tools. Gender equality is central to all the SDGs, but often, women end up on the short end of the means of implementation, in whatever form. While governments increasingly use genderresponsive budgeting to direct funds to programmes that benefit women, these exercises have revealed huge funding gaps in what women need - up to90 per cent. Women have the right to equal access to and benefits from each of the means of implementation. They also need to lead decisions being made, whether in ministries of finance, companies that produce technologies, statistical offices or institutions charged with global economic oversight (Women and Sustainable Development Goals, 2015).

\section{Discussions and Conclusion:}

It can be said that success breeds success and one of the biggest wins for the SwachhataAbhiyan program has been busting of the myth that this is "mission impossible". High-coverage villages and districts were low-hanging fruits. At the same time a relentless focus is maintained on the low coverage states and districts. Considering the most sustainable way for determining scale of operation of programme, the campaign mode of operation leads to success. All initiatives focus on how they can make sanitation a revolution through rapid and community-wide change, and not incrementally. The nationwide Swachhata $\mathrm{Hi}$ Seva initiative during September 15-October 2, where 3 crore people participated in 'SwachhtaShramdaan', was designed based on this insight.Competition and housekeeping are critical for districts. Healthy competition among districts and states spurs innovation in sanitation practices adopted and when there is such speedy acceleration, housekeeping parameters like verification and geo-tagging must keep pace with ODF-declaration (IyerParameswaran, 2017- Times of India dated 21/11/2017).

The women must participate in community decision during the process of determining the sanitation solution such as which technology to be used for toilet construction, safer location of the toilet, and maintenance responsibilities of toilet facilities amongst family members and in the community. This includes needs for sanitation and menstrual hygiene management, as well as needs for elderly and pregnant women (Water and Sanitation Program, 2010). The economic, social and political position of women can be improved through creating the positive impact of water and sanitation service sector as it can address the issue of inequality. The effort to improve sanitation and water supply services would really help to improve the security and health of not only women but also of their families.

The women can tackle their inflexible time by engaging them in social, economic, and political activities which otherwise compel them to spend their time in routine and non-productive tasks, 
perpetuating their absence from decision making and other profitable pursuits (World Bank, 2006).

We need to be aware that the status of women can be changed slowly and gradually as it has deep cultural roots that by nature are slow to adopt the change. But still we must believe that promoting women's active citizenship and voice in community decision especially the sanitation and hygiene conditions has the lot of potential which need to be still workout for empowerment of women (African Development Bank Group, 2015).

\section{References:}

Acharya, DR., Bell, JS.,Simkhada, P., Teijlingen, ER., Regmi, PR. (2010). Women's autonomy in household decision-making: a demographic study in Nepal. Reproductive Health, 7, 15-15.

African Development Bank Group. (2015). Africa Gender Equality Index 2015. Retrieved from http://www.afdb.org/fileadmin/uploads /afdb/Documents/Publications/African Gender_Equality_Index _2015-EN.pdf, on 30/11/2017.

DrPandit, Dipanwita., Dr Kumar, Prasanta., Dr Bhattacharyya, Raja. (2014). Menstrual Hygiene: Knowledge and Practice among Adolescent School Girls In rural areas of West Bengal. IOSR Journal of Dental and Medical Sciences (IOSR-JDMS), 13 (6), 1924.

Goel, Palak., Kumar, Rajesh., Meena G.S, Singh, Tulika., Garg, Suneela (2017). A community based cross sectional study on menstrual hygiene among $18-45$ years age women in a rural area of Delhi. International Journal of Biomedical Research, 8(06), 302-308.

Isobel Davis (2016). Water Supply and Sanitation Collaborative Council (WSSCC), hosted by the United Nations Office for Project Services (UNOPS). http://wsscc.org/wpcontent/ uploads/2016/12/Gender-andCommunity-Led-Total-Sanitation-CLTSengagement-outcomes-and-empowermentin-Malagasy-communities.pdf, Retrieved on $30 / 11 / 2017$.
IyerParameswaran (2017). How Swachh Bharat learns \& adapts. Times of India dated 21/11/2017.

Ministry of Urban Development Government of India Survey 'SwachhSurvekshan 2017', http://swachhsurvekshan.in/SS_2017_Report.pdf, Retrieved on 30/11/2017.

Mudey, AB., Kesharwani, N., Mudey, GA., Goyal, RC. (2010). A cross-sectional study on awareness regarding safe and hygienic practices amongst school going adolescent girls in rural area of Wardha District, India. Global Journal of Health Science. 12(2), 225.

Routray, Parimita., Torondel, Belen., Thomas Clasen., Schmidt, Wolf-Peter (2017). Women's role in sanitation decision making in rural coastal Odisha, India. PLoS One, 2017, 12(5): e0178042,

Seenivasan, P., CarolinePriya, K., Rajeswari, C., Akshaya, C.C., Sabharritha,G. Sowmya, K.R., Banu, Shaheena (2016). Knowledge, attitude and practices related to menstruation among adolescent girls in Chennai. J ClinSci Res 2016; 5:164-70.

Water and Sanitation Program (2010). Gender in Water and Sanitation. Retrieved from https://www.wsp.org /sites/wsp.org/files/publications/WSPgender-watersanitation.pdf, on 30/11/2017.

Women and Sustainable Development Goals (2015). UN Women HQ Communications and Advocacy Section. http://www.cpahq.org/cpahq/cpadocs/2 322UN\%20Women \%20Analysis\%20on $\% 20$ Women\%20and\%20SDGs.pdf, Retrieved on 01/12/2017.

World Bank (2006). Gender, Time Use, and Poverty in Sub- Saharan Africa. World Bank Working paper no. 73, 2006, The International Bank for Reconstruction and Development, Washington, D.C. World Bank. 